\title{
The behavior of dairy cattle in late gestation: Effects of parity and dystocia
}

\author{
R. A. C. Barraclough, ${ }^{1 *}$ ๑ D. J. Shaw,${ }^{1} \odot$ R. Boyce, ${ }^{2}$ M. J. Haskell, ${ }^{3}$ and A. I. Macrae ${ }^{1,4} \oplus$ \\ ${ }^{1}$ Royal (Dick) School of Veterinary Studies and the Roslin Institute, The University of Edinburgh, Easter Bush Campus, Roslin, Midlothian, \\ EH25 9RG, Scotland, United Kingdom \\ ${ }^{2}$ IceRobotics Ltd., Bankhead Steading, Bankhead Road, South Queensferry, Edinburgh, EH30 9TF, Scotland, United Kingdom \\ ${ }^{3}$ Animal Behavior and Welfare, Animal and Veterinary Sciences Research Group, Scottish Agricultural College, West Mains Road, Edinburgh, \\ EH9 3JG, Scotland, United Kingdom \\ ${ }^{4}$ Dairy Herd Health and Productivity Service, Royal (Dick) School of Veterinary Studies and the Roslin Institute, The University of Edinburgh, \\ Easter Bush Campus, Roslin, Midlothian, EH25 9RG, Scotland, United Kingdom
}

\begin{abstract}
The aim of this study was to objectively assess, using an automated behavioral monitoring system, any behavioral differences between primiparous and multiparous cows before calving, and to quantify any behavioral differences between assisted (dystocic) and unassisted (eutocic) calvings. Data were collected from 32 multiparous and 12 primiparous Holstein dairy cattle to describe normal calving behavior and parity differences. To quantify behavior related to calving difficulty, the data from 14 animals that had dystocia at calving were matched to cows that had an eutocic calving based on parity, locomotion score, calf breed, calf sex, month, and year of calving. An IceQube (IceRobotics Ltd., South Queensferry, United Kingdom) was fitted to the right hind leg of cows $4 \mathrm{wk}$ before their expected calving date. Data for lying time, standing time, number of steps, motion index (total motion), and the total number of standing and lying bouts (postural transitions) were automatically collected and summed into 15-min blocks. Behavioral variables were summarized into 2 -h periods and 24-h periods before analyses. Mixed-effect models were used to analyze cow behavior in the last $4 \mathrm{~d}$ before calving ( $\mathrm{d}-4$ to -1 ), and on the day of calving. In the $4 \mathrm{~d}$ before calving, compared with multiparous cows, primiparous cows lay down an average $2.8 \mathrm{~h} / \mathrm{d}$ less, had 9.1 more postural transitions/d ( $37.7 \pm 1.2$ vs. $27.6 \pm 0.7$ ), walked 172 more steps/d, and had a higher motion index (2,673.2 vs. 1,981.5 units/d). There was an effect of 2 -h period on all behavioral variables on the day of calving. No indicator of calving difficulty was found on the day of calving, nor the days leading up to calving. These findings suggest that parity should be considered when predicting the day of calving, and changes in cow behavior on the day of calving could be
\end{abstract}

Received February 15, 2019.

Accepted August 29, 2019.

*Corresponding author: s1677276@sms.ed.ac.uk used to identify calving cows, and to predict the time of calving.

Key words: calving behavior, parturition, calving assistance, dairy cow

\section{INTRODUCTION}

To commence lactation, cows are required to go through parturition, and this process carries many risks. Two common issues at calving are calving difficulty (dystocia) and perinatal mortality, and therefore intensive management of cattle in late pregnancy is critical to ensure neonatal and maternal survival, health, and welfare (Mee, 2004). Dystocia, defined as a difficult or prolonged calving, has been classed as one of the most painful conditions that a cow can experience (Huxley and Whay, 2006). Within the United Kingdom, 16\% of cows are reported to require calving assistance (Wall et al., 2010), and it is estimated that the worldwide prevalence of dystocia in dairy heifers and cows ranges from 1.5 to $22.6 \%$ (Mee, 2008a). To prevent calving difficulties and stillbirth, it is recommended that lategestation cows should be observed frequently for signs of calving. The suggested intervals at which cows are monitored vary from 1 to $2 \mathrm{~h}$ (Gundelach et al., 2009) to 3 to $6 \mathrm{~h}$ (Mee, 2004).

Changes in cow behavior have been observed on the day of calving, compared with the days leading up to calving. Jensen (2012) reported that overall lying time gradually decreased from $4 \mathrm{~d}$ pre-calving (998 min) until the day of calving (894 min). When data were analyzed in 2-h blocks on the day of calving, it was observed that lying time increased in the last $12 \mathrm{~h}$ before calving from $31.4 \mathrm{~min} / 2 \mathrm{~h}$ to $42.8 \mathrm{~min} / 2 \mathrm{~h}$ just before calving. Overall activity has been reported to increase on the day of calving, and this is attributed to pain around calving. The number of postural transitions on the day of calving increases by up to $80 \%$ when compared with a noncalving control period (Huzzey et al., 2005), and tail raising was shown to increase in the 2- to 6 -h 
period before calving (Miedema et al., 2011b; Barrier et al., 2012). On the day of calving, Schirmann et al. (2013) reported a 15\% reduction in rumination, a $24 \%$ decrease in DMI, and a $32 \%$ reduction in the time spent feeding when compared with 2 to $4 \mathrm{~d}$ before calving.

Cows that calved with dystocia exhibit restless behavior earlier than cows that calved with no assistance (Wehrend et al., 2006). In the $24 \mathrm{~h}$ before calving, Proudfoot et al. (2009) observed that cows with dystocia had more frequent transitions from standing to lying when compared with cows without dystocia. In contrast, Miedema et al. (2011a) and Barrier et al. (2012) reported no interaction between the number of postural changes from lying to standing between cows with assisted calvings and cows with unassisted calvings. Kovács et al. (2017) found that cows with dystocia had lower rumination times in the final $8 \mathrm{~h}$ before calving when compared with cows that had unassisted calvings. However, this result was not statistically significant.

As herd size increases and the availability of skilled labor decreases, there is a need to apply user-friendly, automated technology to facilitate herd management (Gargiulo et al., 2018). Remote sensing devices have the potential to improve animal behavior monitoring as they can continuously and automatically measure animal activity without altering the animal's natural behavior (Theurer et al., 2013). The aim of this study was to objectively assess, using an automated behavioral monitoring system, any behavioral differences between primiparous and multiparous cows before calving, and to quantify any behavioral differences between dystocic and eutocic calvings.

\section{MATERIALS AND METHODS}

\section{Animals and Housing}

The study was conducted at the University of Edinburgh Langhill Farm (Roslin, Midlothian, United Kingdom) between November 2016 and April 2018. The experimental work was approved by The Royal Dick School of Veterinary Studies Veterinary Ethical Review Committee (reference 82-16). The farm has a milking herd of approximately 220 Holstein cows. The calving environment was a straw-bedded shed $(11 \mathrm{~m} \times 18.4 \mathrm{~m})$ that was kept at a stocking rate of 5 to 15 heifers and cows. Cows had a space allowance of between 11.1 and $33.2 \mathrm{~m}^{2}$ on a straw-bedded area, and a space allowance of between 2.4 and $7.3 \mathrm{~m}^{2}$ on a concrete loafing area. Animals were moved into the straw-bedded calving shed approximately $6.8 \pm 4.6 \mathrm{~d}$ before their actual calving date. Once a day, cows were fed a TMR consisting of grass silage, wholecrop, concentrate, molasses, and dry cow mineral. The ration had a 4:1 forage:concentrate ratio. Cows had access to self-filling water troughs $(0.95$ $\mathrm{m} \times 0.4 \mathrm{~m} \times 0.35 \mathrm{~m}$ ), which supplied municipal water. The decision to give assistance at calving was based on farm protocol. Assistance was given if calving was progressing slowly (if calving progress had ceased over a 30-min period, or if the calf started to show signs of reduced vigor; Mee, 2008b) or if the calf was not presented normally. Ease of calving was recorded using a farm specific 5-point scale: (1) no assistance, (2) gentle traction by one person with no mechanical device used, (3) use of calving jack or assistance with 2 persons, (4) veterinary assistance, and (5) cesarean section. Calving scores of 2 or above were classed as assisted calving.

\section{Behavioral Measurements}

An IceQube (IceRobotics Ltd., South Queensferry, United Kingdom) was fitted to the right hind leg of each cow 4 wk before the predicted calving date. The IceQube is a triaxial accelerometer that sampled cow behavior at $4 \mathrm{~Hz}$ and summarized lying times, standing times, the number of steps, the number of postural transitions from standing to lying, and motion index into 15-min blocks (Elischer et al., 2013; Borchers et al., 2016). Motion index is the sum of net acceleration measured by the 3 -axis minus an offset for gravity, and motion index can be considered an expression of leg activity (Maselyne et al., 2017).

Observations for time of calving were made when cows were housed in the straw yard calving shed. One webcam (AXIS P5414-E PTZ Network Camera), with HDTV 720p performance and $18 \times$ optical zoom, was installed in an overhead position that gave a good overview of the calving shed. A timestamp (hour:min:sec) and a date (year:month:day) were visible on all video files. The time and date were automatically synchronized with the computer's clock. The calving shed was lit naturally by sunlight during daylight hours (0800$1600 \mathrm{~h}$ ) and artificial lighting remained on during the night (1600-0800 h). The exact time of calving (to the nearest minute) was ascertained by retrospective analysis of video recordings. The time of calving was taken to be the point where the fetus was fully expelled from the cow or when the calf's hips were expelled, and the hind legs remained inside the birth canal. This occurred at the end of stage II of parturition and was a comparable definition to previous studies (Campler et al., 2015). Parturition occurs in 3 stages: stage I, stage II, and stage III. Stage I consists of cervical dilation, the start of myometrial contractions, and placement of the fetus before expulsion. Stage II includes visible abdominal contractions, the rupture of the allantochorionic sac and fetal expulsion from the birth canal. The final stage of 
parturition, stage III, consists of fetal membrane expulsion (Mainau and Manteca, 2011).

\section{Statistical Analysis}

Data set 1 was used to analyze normal calving behavior and parity differences, and consisted of 44 animals: 12 primiparous cows and 32 multiparous cows (calving score 1 , parity $0-7$, mean $1.2 \pm 0.2$ ). Animals within data set 1 calved between 2016 and 2017 .

Data set 2 was used to analyze the difference in behavior between animals that had dystocic calvings ( $\mathrm{n}$ $=14$; calving score of 2 or above; parity $0-3$, mean 1.1 $\pm 0.1)$ and animals that had eutocic calvings $(\mathrm{n}=14$; calving score 1 ; parity $0-3$, mean $1.1 \pm 0.1$ ). The 14 eutocic cows included 8 cows from data set 1 (7 multiparous, 1 primiparous) and 4 separate eutocic cows that calved between 2017 and 2018. Animals within data set 2 calved between 2016 and 2018. A case-control study design was used to compare the behavioral difference between animals that had dystocic calvings and animals that had eutocic calvings. The 14 animals with dystocic calvings were exactly matched to cows that had an eutocic calving based on lactation number $(\mathrm{n}=$ 14 pairs), calving date $\pm 28 \mathrm{~d}$ ( $\mathrm{n}=14$ pairs), and year of calving ( $\mathrm{n}=14$ pairs). Cows were also matched as closely as possible based on locomotion score $(\mathrm{n}=11$ pairs), calf breed ( $\mathrm{n}=9$ pairs), calf sex ( $\mathrm{n}=12$ pairs). Of the 14 animals that calved with dystocia, 9 cows were assisted by gentle traction (score 2) and 5 cows were calved with a calving jack (score 3 ).

A further 54 animals were observed but excluded from the analysis for various reasons including incomplete data sets $(\mathrm{n}=2)$, presence of clinical milk fever $(\mathrm{n}=15)$, severe lameness $(\mathrm{n}=3$; mobility score 2 and 3 using 0-3 point scale: AHDB 2018), no recorded time of calving $(\mathrm{n}=10)$, or were not present in the straw yard for $>5 \mathrm{~d}(\mathrm{n}=24)$. Only cows that were present in the straw yard for 5 or more days before the day of calving were used for the analyses to ensure cows were within the same environment when analyses were conducted.

To investigate the behavior of dairy cattle in late gestation, the duration of lying time, the number of steps, the motion index, and the total number of standing and lying bouts (the number of postural positions) from data set 1 and data set 2 were each summarized from the time of calving into 2 data sets: behavior in 2 -h periods and 24 -h periods (behavior per day). The bihourly data sets were used for the analyses of cow behavior on the day of calving, and data were analyzed in 2 -h periods from -24 to $0 \mathrm{~h}$ (the time of calving). The data set containing cow behavior per day were used to analyze cow behavior in the days before calving $(\mathrm{d}-4$ to -1 ), and to compare the change in behavior on the day of calving (d 0) compared with a control period (d $-4)$. In this study, the number of lying and standing bouts were combined to provide a value for the number of postural of transitions within a period. All data sets were summed from the time relative to calving (i.e., calving was used as time 0), which ensured all cows followed the same timeline.

All analyses and data manipulations were carried out using R (version 3.4.4; R Foundation for Statistical Computing, Vienna, Austria). To assess data assumptions of normality, residual plots, histogram plots, and data normality tests were examined. Mixed-effect analyses were carried out using the 'ImerTest' package. Residual plots were examined to ascertain the best model fit for the data. Statistical significance was taken as $P \leq 0.05$. Nonsignificant $(P>0.05)$ interactions were removed from models. Degrees of freedom were calculated using the Satterthwaite approximation for linear models and polynomial regression models, while Laplace approximation was used to calculate degrees of freedom for generalized piecewise regression models.

Behavioral Differences Between the Day of Calving and Control Period. To explore the behavioral changes that occur on the day of calving (d 0) compared with a control period $(\mathrm{d}-4)$, the duration and frequencies of behaviors in each 24 -h period were compared for primiparous cows $(\mathrm{n}=12)$, multiparous cows $(\mathrm{n}=32)$, dystocic cows $(\mathrm{n}=14)$, and eutocic cows $(\mathrm{n}=14)$. The step count and motion index were $\log _{10}$ transformed to meet normal residual data distribution assumptions. Paired $t$-test were used to analyze normally distributed data (lying time, step count, and motion index), and Wilcoxon signed rank tests were used to analyze non-normally distributed data that did not fit normal data assumptions after $\log _{10}$ transformation (the number of postural transitions). In this study, there was no difference between behavior variables on $\mathrm{d}-4$ and -3 when each variable was compared using the appropriate statistical test, so $\mathrm{d}-4$ was chosen as the control period.

Last 4 d Before Calving. For further investigation of the behavioral differences between primiparous cows and multiparous cows, and between dystocic and eutocic cows in late gestation, a linear mixed-effect model was used to assess behavioral changes in the last $4 \mathrm{~d}$ before calving ( $\mathrm{d}-4$ to -1 ). To investigate behavioral differences between primiparous $(\mathrm{n}=12)$, and multiparous cows $(\mathrm{n}=32)$, the linear mixed-effect model included days to calving ( $\mathrm{d}-4, \mathrm{~d}-3, \mathrm{~d}-2$, and $\mathrm{d}-1$ ), parity (multiparous and primiparous), and the interaction between days to calving and parity as fixed effects, and cow ID was included as a random effect to account for repeated measurements per cow. The data set contained 176 data points, and each cow 
had 4 repeated observations. To investigate behavioral differences between dystocic $(\mathrm{n}=14)$ and eutocic $(\mathrm{n}=$ 14) cows, the linear mixed-effect model included days to calving ( $\mathrm{d}-4,-3,-2$, and -1 ), assistance level at calving (dystocia and eutocia), and the interaction between days to calving and assistance level at calving as fixed effects. To account for repeated measurements per cow, and the pair that cows were assigned to, a nested random effect containing pair and cow ID was used (pair/cow ID). The data set contained 112 data points, and each cow had 4 repeated observations. Animals were pair matched using lactation number, and as this variable was already controlled for within the random effect, parity (multiparous and primiparous) was not included in the final model. The step count and motion index were $\log _{10}$ transformed to meet normal residual data distribution assumptions.

Last $24 h$ Before Calving. To ascertain the pattern of behavior exhibited on the day of calving, a set of mixed-effect models with different temporal relationships were fitted to behavioral variables contained within the bihourly data set. Data were analyzed over twelve 2 -h periods from $-24 \mathrm{~h}$ to $0 \mathrm{~h}$ (the time of calving). A generalized piecewise regression models (or "broken-stick" models, where a step change in behavior at a certain time point is observed; Das et al., 2016), polynomial regression models (where there is either a decrease and then increase, or increase and then decrease in behaviors; Ostertagová, 2012), and linear models (Bangdiwala, 2018) were fitted to each behavioral variable. Residual plots were examined to ascertain the best model fit for the data. A piecewise regression model provided the best description of the change in the number of postural transitions, whereas a polynomial regression model best described the change in lying time. Linear models best described the change in step count and motion index. To investigate behavioral differences between primiparous $(\mathrm{n}=12)$ and multiparous cows $(\mathrm{n}=32)$, each model included time relative to calving ( -24 to $0 \mathrm{~h}$ ), parity (multiparous and primiparous), and the interaction between time relative to calving and parity as fixed effects, and cow ID was included as a random effect to account for repeated measurements per cow. The data set contained 528 data points, and each cow had 12 repeated observations. To investigate behavioral differences between dystocic $(\mathrm{n}=14)$ and eutocic cows $(\mathrm{n}=14)$, each model included time relative to calving ( -24 to $0 \mathrm{~h}$ ), assistance level at calving (dystocia and eutocia), and the interaction between time relative to calving and assistance level at calving as fixed effects. To account for repeated measurements per cow, and the pair that cows were assigned to, a nested random effect containing pair and cow ID was used (pair/cow ID). The data set contained 336 data points, and each cow had 12 repeated observations. The step count and motion index were $\log _{10}$ transformed to meet normal residual data distribution assumptions.

\section{RESULTS}

\section{Behavioral Differences Between the Day of Calving and Control Period}

The lying time (h/d) of primiparous cows, multiparous cows, dystocic cows, and eutocic control cows decreased on the day of calving when compared with a control period $(\mathrm{d}-4)$ (Table 1$)$. On the day of calving, the average number of postural transitions increased by $29.6 \%$ for primiparous cows $\left(v_{11}=0, P<0.01\right), 45.6 \%$ for multiparous cows $\left(v_{31}=-14.5, P<0.01\right), 42.4 \%$ for dystocic cows $\left(v_{13}=6, P<0.01\right)$, and $44.0 \%$ for eutocic control cows $\left(v_{13}=8, P<0.01\right)$ when compared with the control period (Table 1). There were no differences in the average number of steps (no./d) and motion index (unit/d) in primiparous cows on the day of calving when compared with the control period. In contrast, the step count of multiparous cows $\left(t_{31}=-4.09, P\right.$ $<0.001)$, dystocic cows $\left(t_{13}=-3.72, P<0.01\right)$, and eutocic control cows $\left(t_{13}=-2.62, P<0.05\right)$ increased on the day of calving when compared with the control period (Table 1). Additionally, the motion index of multiparous cows $\left(t_{31}=-5.84, P<0.001\right)$, dystocic cows $\left(t_{13}=-4.41, P<0.001\right)$, and eutocic control cows $\left(t_{13}=-3.65, P<0.001\right)$ also increased on the day of calving compared with the control period (Table 1).

\section{Last 4 d Before Calving}

While the lying time of multiparous cows remained constant in the $4 \mathrm{~d}$ before the day of calving (14.2 \pm $\left.0.2 \mathrm{~h} ; F_{1,95}=0.11, P=0.74\right)$, the lying time of primiparous cows decreased by $25 \mathrm{~min} / \mathrm{d}(13.0 \pm 0.4 \mathrm{~h}$ to $11.6 \pm 0.6 \mathrm{~h} ; F_{1,35}=7.62, P=0.009$; Figure 1a). A difference was observed in the pattern of the lying time (h/d) depending on parity, with primiparous cows on average $-2.8 \mathrm{~h} / \mathrm{d}$ lower than that of multiparous cows across the period $\left(F_{1,94}=17.3, P<0.001\right)$. No interaction was observed between days to calving and parity on the number of postural transitions $\left(F_{1,130}=0.04\right.$, $P>0.83$, Figure $1 \mathrm{~b}$ ), nor an effect of days to calving $\left(F_{1,130}=0.67, P>0.60\right.$, Figure $\left.1 \mathrm{~b}\right)$. Primiparous cows had an average of $9.1 \pm 2.4$ more postural transitions per day compared with multiparous cows $\left(F_{1,42}=13.9\right.$, $P<0.001)$. There was a decrease in both step count and motion index across the period $(P<0.041$, Figure $1 \mathrm{c}, \mathrm{d})$. In addition, the step count (steps $/ \mathrm{d} ; F_{1,42}=11.1$, $P=0.002)$ and motion index (unit $/ \mathrm{d} ; F_{1,42}=14.5, P<$ 


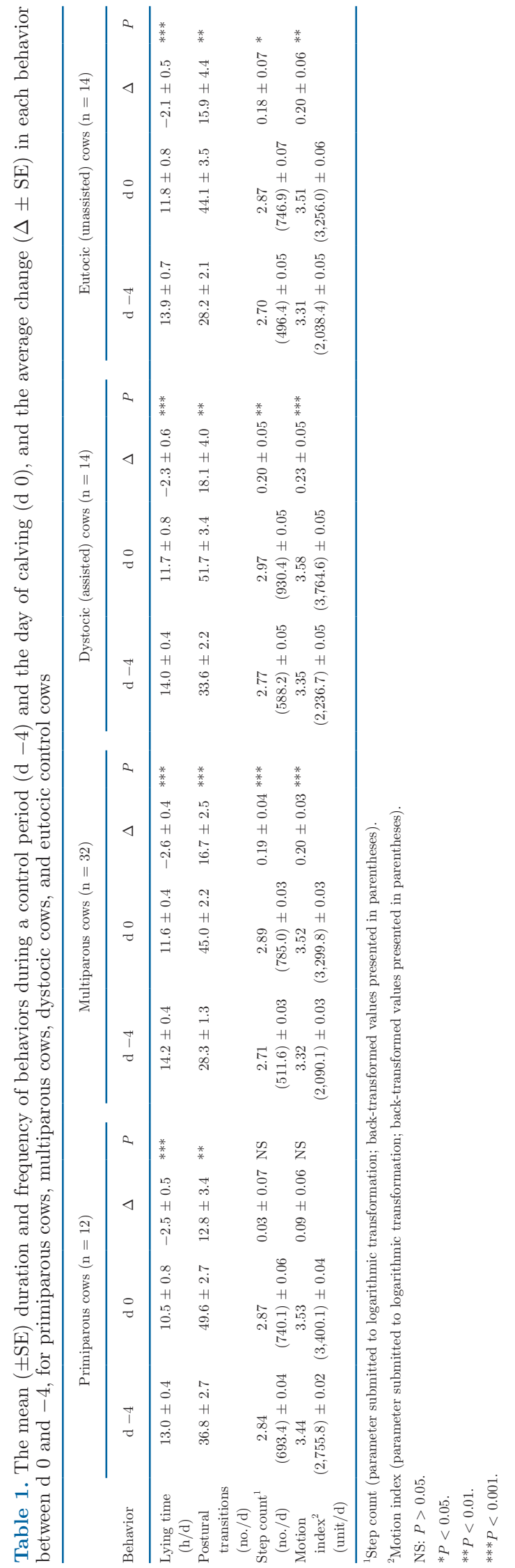

0.001 ) of primiparous cows was on average $14 \%$ higher per day when compared with multiparous cows.

\section{Last 24 h Before Calving}

No interaction was observed between lying time $(\mathrm{min} / 2 \mathrm{~h})$ and parity $\left(F_{1,480}=3.65, P=0.06\right.$; Figure 2a), nor was an effect detected of parity on lying time $\left(F_{1,274}=0.29, P=0.59\right)$ on the day of calving. The change in lying time on the day of calving for primiparous and multiparous cows was best described by a polynomial pattern, with a decline from $65.3 \mathrm{~min} / 2 \mathrm{~h}$ at $-22 \mathrm{~h}$ to a low of $50.6 \mathrm{~min} / 2 \mathrm{~h}$ at $-12 \mathrm{~h}$, increasing to an average of $66.8 \mathrm{~min} / 2 \mathrm{~h}$ just before birth $\left(F_{1,482}\right.$ $=9.3, P=0.002)$. A piecewise regression model provided the best description of the change in the number of postural transitions on the day of calving for both primiparous and multiparous cows, with a combined breakpoint of $-6.3 \mathrm{~h}$ (Figure $2 \mathrm{~b}$ ). There was an effect of parity on the number of postural transitions on the day of calving, with primiparous cows having an average of 0.24 more postural transitions in each 2 -h period compared with multiparous cows $\left(z_{1,482}=1.96\right.$, $P<0.05)$. In addition, increases were observed in the average number of postural transitions in primiparous and multiparous cows from 4.4 and 3.2 at the breakpoints to 10.0 and 10.6 just before birth, respectively $(P<0.001)$. When a piecewise regression model was run separately for primiparous and multiparous cows, the individual breakpoints calculated were -2.0 and $-6.6 \mathrm{~h}$, respectively. There was no interaction between parity and hours to calving for step count $\left(F_{1,482}=3.3\right.$, $P>0.05$; Figure 2c) and motion index $\left(F_{1,482}=1.86\right.$, $P>0.05$; Figure 2d), nor an overall effect of parity on either step count $\left(F_{1,144}=3.0, P=0.09\right)$ or motion index $\left(F_{1,155}=0.72, P>0.05\right)$. Linear changes in both step count $\left(F_{1,483}=16.5, P<0.001\right)$ and motion index $\left(F_{1,483}=47.9, P<0.001\right)$ on the day of calving were observed, with increases in both parameters. Back transformation of $\log _{10}$ data show that step count increased from an average of 32.3 steps $/ 2 \mathrm{~h}$ at $-22 \mathrm{~h}$ to 78.8 steps $/ 2 \mathrm{~h}$ just before calving, and motion index increased from an average of 139.5 unit/2 h at -22 to 437.5 unit/ 2 h just before calving.

\section{Last 4 d Before Calving: Dystocic and Eutocic}

Within the $4 \mathrm{~d}$ before calving $(\mathrm{d}-4,-3,-2$, and -1 ), there was no difference between the 14 dystocic cows, and the 14 eutocic cows for the duration of lying time $(\mathrm{h} / \mathrm{d})$, the number of postural transitions (no./d), the step count (no./d), and the motion index (unit/d; $P>0.36)$. There was no interaction between days to calving and assistance level at calving for the duration 
of lying time, step count, and motion index within the period $(P>0.12)$. In contrast, there was an interaction between the number of postural transitions and assistance level at calving $\left(F_{1,82}=6.3 ; P=0.01\right)$, which decreased from $33.6 \pm 2.2$ to $29.1 \pm 2.0$ for dystocic cows, but increased from $28.2 \pm 2.1$ to $30.4 \pm 1.6$ in the 14 eutocic cows.

\section{Last 24 h Before Calving: Dystocic and Eutocic}

On the day of calving, no interaction was observed between hours to calving and assistance level at calving on lying time $\left(\mathrm{min} / 2 \mathrm{~h} ; F_{1,304}=0.01, P=0.92\right)$, nor a difference in the lying time between dystocic and eutocic cows $\left(F_{1,26}=0.06, P=0.81\right)$. The change in lying time on the day of calving for dystocic and eutocic cows was best described by a polynomial pattern, with a decline from 61.8 at $-22 \mathrm{~h}$ to a low of 51.6 at $-10 \mathrm{~h}$, increasing to an average of 66.4 just before birth $\left(F_{1,306}\right.$ $=4.7 P=0.03)$. Piecewise regression models provided the best description of the change in the number of postural transitions. The calculated breakpoint for the number of postural transitions was $-11.0 \mathrm{~h}$ in dystocic cows, and $-8.5 \mathrm{~h}$ for eutocic cows. Before the break- points, hours to calving had no effect on the number of postural transitions for both dystocic and eutocic cows $\left(z_{1,306}=0.11, P=0.91\right)$. In contrast, after breakpoints, hours to calving had an effect on the number of postural transitions for both dystocic and eutocic cows $\left(z_{1,306}=\right.$ 16.1, $P<0.001)$, with the average number of postural transitions increasing by an average of 0.16 and 0.15 , respectively, every $2 \mathrm{~h}$. No difference was observed in the number of postural transitions between dystocic and eutocic cows on the day of calving $\left(z_{1,26}=-1.68\right.$, $P=0.07)$. On the day of calving, no interaction was observed between assistance level and hours to calving on step count $\left(F_{1,306}=0.25, P=0.61\right)$ and motion index $\left(F_{1306}=0.27, P=0.60\right)$, nor was an overall effect of assistance level observed on either step count $\left(F_{1,26}=\right.$ $1.91, P=0.18)$ or motion index $\left(F_{1,26}=1.6, P=0.22\right)$. Linear changes in both step count and motion index on the day of calving were observed, with increases in both parameters $(P<0.001)$. Back transformation of $\log _{10}$ data show that step count increased from an average of 35.2 steps $/ 2 \mathrm{~h}$ at $-22 \mathrm{~h}$ to 83.5 steps $/ 2 \mathrm{~h}$ just before calving, and motion index increased from an average of 157.8 unit/2 h at -22 to 443.3 unit/ $2 \mathrm{~h}$ just before calving.
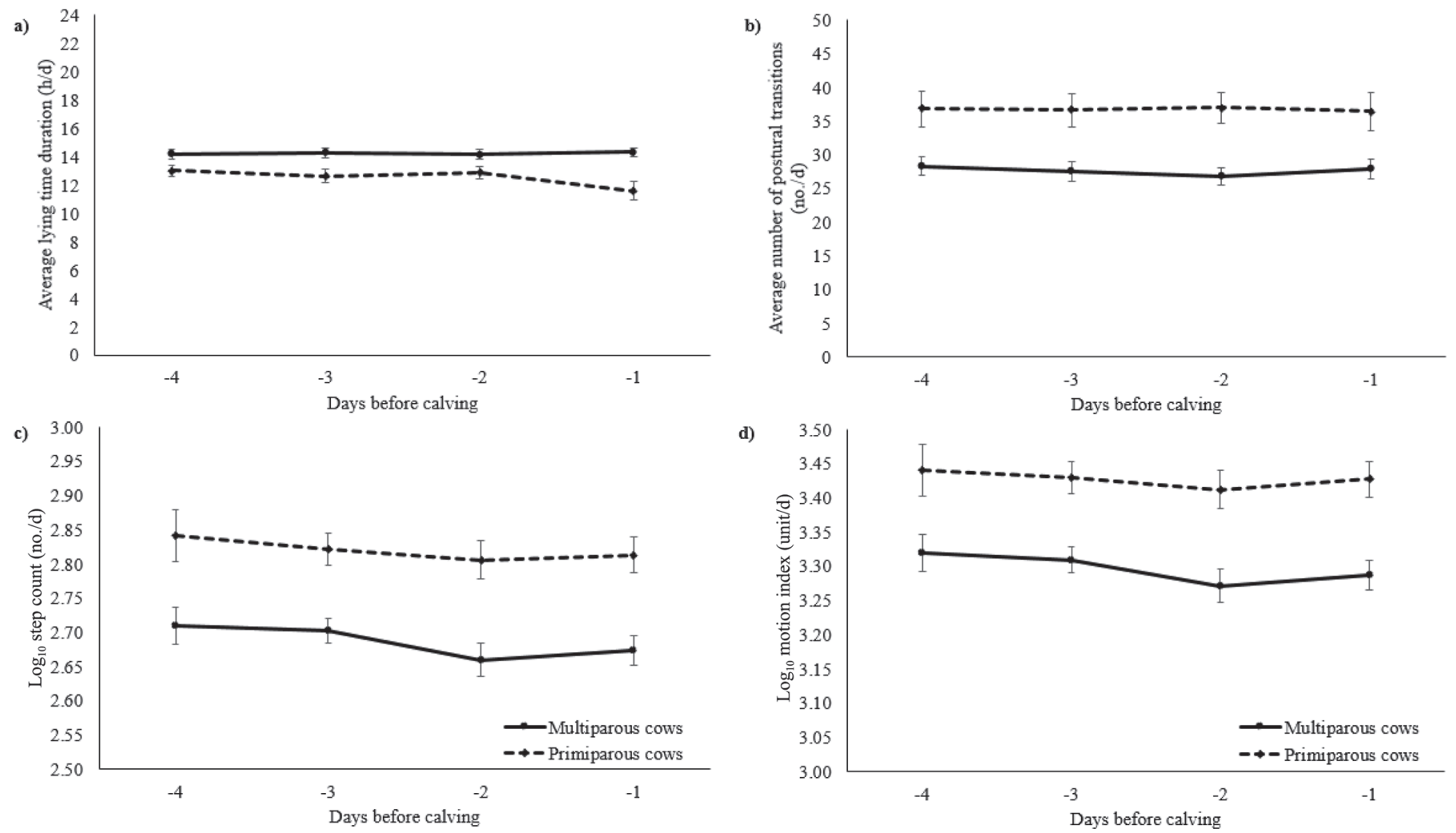

Figure 1. Behavioral variables for primiparous cows (dashed line; $\mathrm{n}=12$ ) and multiparous cows (solid line; $\mathrm{n}=32$ ) summarized into 24-h periods \pm SE in the $4 \mathrm{~d}$ before calving for (a) lying time duration, (b) number of postural transitions, (c) $\log _{10}$ step count, and (d) $\log _{10}$ motion index. 


\section{DISCUSSION}

For multiparous cows, dystocic cows, and eutocic control cows, all behavioral variables were significantly different on the day of calving compared with the control period $(\mathrm{d}-4)$. On the day of calving, the number of postural transitions increased by $29.6 \%$ for primiparous cows and $45.6 \%$ for multiparous cows when compared with the control period. This study combined the number of lying bouts and standing bouts to represent the total number of postural transitions in a period. The number of lying bouts and standing bouts are comparable measurements, as the number of lying and standing bouts a cow takes in a day are proportional to each other. Similar to this study, Miedema et al. (2011b) reported that the number of lying bouts increased on the day of calving when compared with a control period and Huzzey et al. (2005) reported an $80 \%$ increase in the number of standing bouts on the day of calving. This study found that lying time decreased by an average of $-2.55 \mathrm{~h}$ for primiparous and multiparous cows on the day of calving compared with the control period.
In the last $4 \mathrm{~d}$ before calving ( $\mathrm{d}-4$ to -1 ), parity differences were observed for all behavioral variables. The lying time of primiparous cows was $-2.8 \mathrm{~h} / \mathrm{d}$ lower than that of multiparous cows and lying time decreased by approximately $25 \mathrm{~min} / \mathrm{d}$ within the period. In contrast, the lying time of multiparous cows remained constant. Borchers et al. (2017) reported a similar finding and showed that the lying time of primiparous cows decreased in the last $7 \mathrm{~d}$ before calving and was lower than that of multiparous cows. Primiparous cows had numerically more standing and lying bouts per day compared with multiparous cows, which has been reported in previous studies (Lobeck-Luchterhand et al., 2015; Neave et al., 2017). After controlling for milk production and BW, Neave et al. (2017) still observed differences in the number of postural transitions during the transition period. This finding shows that differences in the standing and lying bout behavior are independent of these 2 variables. The number of steps and total motion index decreased across the period; however, the number of steps/d and motion index/d were higher for primiparous cows. Wehrend et al.
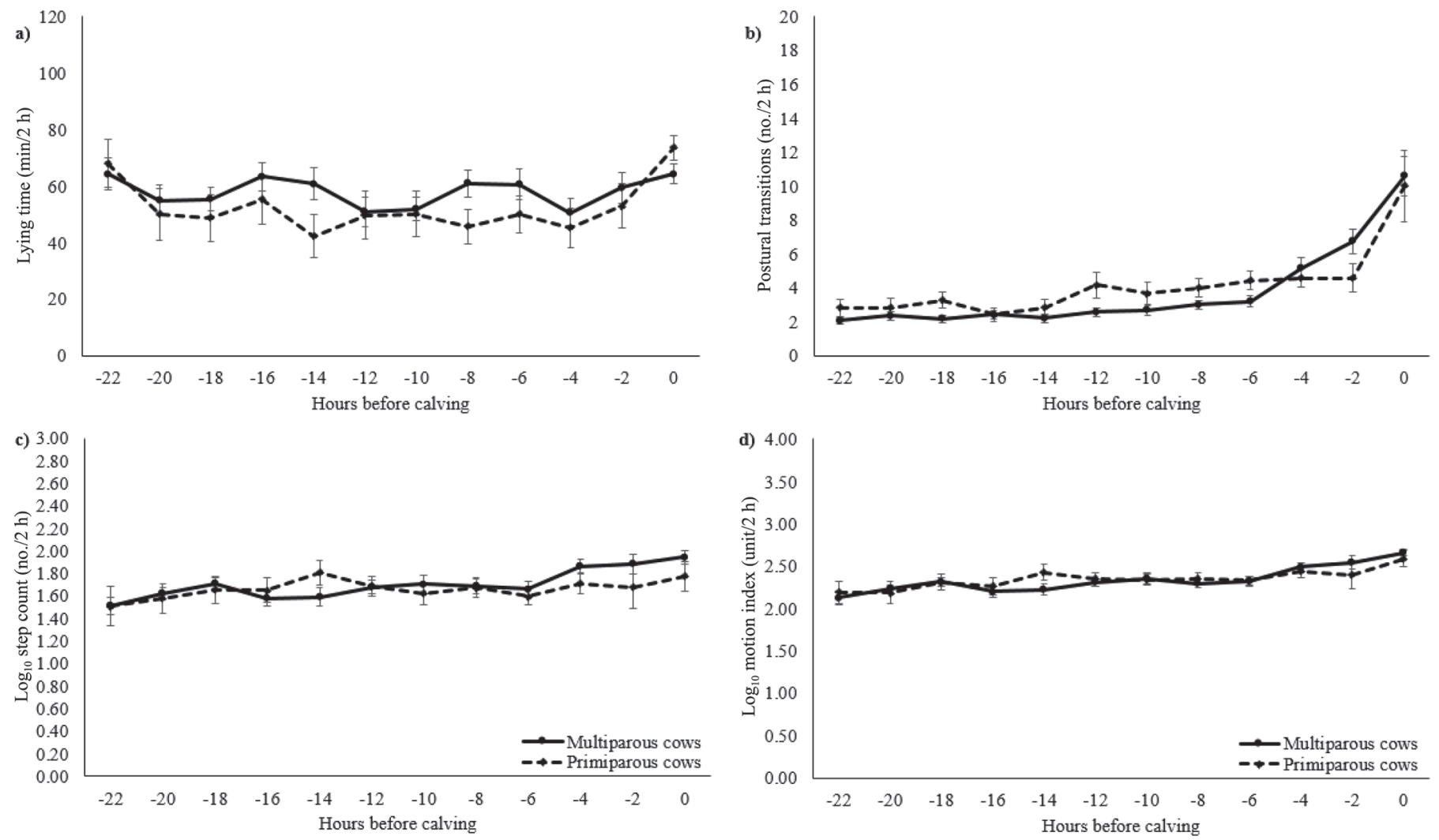

Figure 2. Behavioral variables for primiparous cows (dashed line; $\mathrm{n}=12$ ) and multiparous cows (solid line; $\mathrm{n}=32$ ) summarized into 2 - $\mathrm{h}$ periods $\pm \mathrm{SE}$ in the $24 \mathrm{~h}$ before calving for (a) lying time duration, (b) number of postural transitions, (c) $\log _{10}$ step count, and (d) $\log _{10}$ motion index. 
(2006) reported primiparous cattle to be more restless as parturition approached, and this could explain the parity differences for all behavioral variables in the days leading to calving.

This study fitted mixed-effect models with different temporal relationships to describe the pattern of behavior exhibited in the $24 \mathrm{~h}$ before calving. Piecewise regression was a novel technique used for the analysis of the precalving behavioral data in this study, and allowed the time when behavior changes before calving to be estimated. On the day of calving, there was an effect of 2 -h period on all behavioral variables, and this finding indicates that labor has an effect on cow behavior. An increase in the number of postural transitions on the day of calving has been reported in previous literature (Huzzey et al., 2005; Jensen, 2012), and could be explained by cows having a greater degree of pain as they enter stage II of parturition. Stage II is characterized by uterine contractions, appearance of the amniotic sac, and expulsion of the fetus. In this study, the lying time of cows increased in the last 12 $\mathrm{h}$ before calving and peaked $2 \mathrm{~h}$ before calving. It has been reported that cows typically lie down more as the fetus enters the birth canal (Schuenemann et al., 2011). Expulsion of the fetus has been reported to take an average of $69.7 \mathrm{~min}$ from the appearance of the amniotic sac (Schuenemann et al., 2011). The peak in lying time $2 \mathrm{~h}$ before calving in this study can be explained by cows lying down to expel the fetus from the birth canal.

Previous studies have described the effect of parity on cow behavior on the day of calving (Wehrend et al., 2006; Miedema et al., 2011a; Schuenemann et al., 2011). In the present study, there were no numerical differences in lying time duration, step count, or motion index when multiparous and primiparous cows were compared on the day of calving; however, primiparous cows had numerically more postural transitions compared with multiparous cows. Wehrend et al. (2006) reported that fewer primiparous cows exhibited calm behavior on the day of calving, and this restlessness behavior may explain why primiparous cows had more postural transitions than multiparous cows. Similar findings were observed by Schuenemann et al. (2011), and it was reported that primiparous cows had an increase in the number of transitions from lying-standing at the start of labor stage.

The behavior of dystocic cows in the days leading up to calving has not been widely explored in the literature. Previous studies have typically focused on the behavior of dystocic cows on the day of calving. This study found no numerical difference in the lying time duration, the number of steps, and the motion index between dystocic and eutocic cows in the last $4 \mathrm{~d}$ before calving. An interaction was observed between the num- ber of postural transitions and the level of assistance at calving. The average number of postural transitions decreased for dystocic cows across the period, from 33.6 $\pm 2.2(\mathrm{~d}-4)$ to $29.1 \pm 2.0(\mathrm{~d}-1)$. Proudfoot et al. (2009) reported that cows that calved with dystocia had numerically more postural transitions on the day of calving compared with cows that did not require assistance at calving. Although this study found that breakpoints occurred earlier on the day of calving for dystocic cows $(-11.0 \mathrm{~h})$ compared with eutocic cows $(-8.5 \mathrm{~h})$, no numerical difference was observed in the number of postural transitions. Proudfoot et al. (2009) categorized assistance at calving into 2 categories: easy assistance (one person was required to pull the calf out), and difficult assistance ( 2 people were required to pull the calf out). Only cows that were classed as having difficult assistance were used in the study. This study included cows that had minor assistance at calving (gentle traction by one person with no mechanical device used), and the decision of the farm staff to assist cows by a gentle traction may have confounded the data. Cows that were classed as eutocic within this study may have experienced the same low level of difficulty at calving as cows that were calved with gentle traction, however, were unassisted due to management factors (i.e., night-time calving). It is possible that comparing eutocic cows with cows that had a greater degree of assistance at calving could highlight behavioral differences in the days leading to calving. It is suggested that the earlier breakpoint calculated for dystocic cows is indicative of dystocic cows spending more time in labor before the calf was expelled from the birth canal (Barrier et al., 2012).

Farmers currently rely on expected calving dates to manage cows around calving, and direct observations to identify calving cows. Automated monitoring of cow behavior has the potential to provide farmers with a more accurate indicator of the day and time of calving when compared with the expected calving date. For dairy farmers, predictions of the day or time of calving have the benefit of ensuring that intervention, where appropriate, can be given in a timely manner. Currently, there is no automated method to predict which cows may need assistance at calving, and an accurate monitoring system to identify calving cows could improve neonatal and maternal survival, health, and welfare. This study found important differences in the behavior of primiparous cows and multiparous cows, which suggest that parity must be considered when predicting the day of calving. Although no indicator of calving difficulty was identified by this research, the ability to identify calving cows and to predict the time of calving would allow farmers to monitor the progression of calving and intervene where necessary. 


\section{CONCLUSIONS}

The behavior of dairy cattle undergoes numerous changes on the day of calving. Although parity differences were observed in the $4 \mathrm{~d}$ preceding calving, no differences were present in parity on the day of calving for duration of lying time, step count, or motion index. It is suggested that parity must be considered when predicting the day of calving. No indicator of calving difficulty was identified by this research.

\section{ACKNOWLEDGMENTS}

This work was funded by a Biotechnology and Biological Sciences Research Council (BBSRC), East of Scotland BioScience Doctoral Training Partnership (EASTBIO DTP), Collaborative Awards in Science and Engineering (CASE) studentship (RB), and the industrial partner was IceRobotics Ltd.

\section{REFERENCES}

AHDB. 2018. AHDB Mobility Scoring Instructions. Accessed Oct. 30, 2018. https://dairy.ahdb.org.uk/resources-library/technical -information/health-welfare/mobility-score-instructions / \# .W9cQBIX7SUk.

Bangdiwala, S. I. 2018. Regression: Simple linear. Int. J. Inj. Contr. Saf. Promot. 25:113-115.

Barrier, A. C., M. J. Haskell, A. I. Macrae, and C. M. Dwyer. 2012. Parturition progress and behaviors in dairy cows with calving difficulty. Appl. Anim. Behav. Sci. 139:209-217.

Borchers, M. R., Y. M. Chang, K. L. Proudfoot, B. A. Wadsworth, A. E. Stone, and J. M. Bewley. 2017. Machine-learning-based calving prediction from activity, lying, and ruminating behaviors in dairy cattle. J. Dairy Sci. 100:5664-5674.

Borchers, M. R., Y. M. Chang, I. C. Tsai, B. A. Wadsworth, and J. M. Bewley. 2016. A validation of technologies monitoring dairy cow feeding, ruminating, and lying behaviors. J. Dairy Sci. 99:74587466.

Campler, M., L. Munksgaard, and M. B. Jensen. 2015. The effect of housing on calving behavior and calf vitality in Holstein and Jersey dairy cows. J. Dairy Sci. 98:1797-1804.

Das, R., M. Banerjee, B. Nan, and H. Zheng. 2016. Fast estimation of regression parameters in a broken-stick model for longitudinal data. J. Am. Stat. Assoc. 111:1132-1143.

Elischer, M. F., M. E. Arceo, E. L. Karcher, and J. M. Siegford. 2013. Validating the accuracy of activity and rumination monitor data from dairy cows housed in a pasture-based automatic milking system. J. Dairy Sci. 96:6412-6422.

Gargiulo, J. I., C. R. Eastwood, S. C. Garcia, and N. A. Lyons. 2018. Dairy farmers with larger herd sizes adopt more precision dairy technologies. J. Dairy Sci. 101:5466-5473.

Gundelach, Y., K. Essmeyer, M. K. Teltscher, and M. Hoedemaker. 2009. Risk factors for perinatal mortality in dairy cattle: Cow and foetal factors, calving process. Theriogenology 71:901-909.

Huxley, J. N., and H. R. Whay. 2006. Current attitudes of cattle practitioners to pain and the use of analgesics in cattle. Vet. Rec. 159:662-668.
Huzzey, J. M., M. A. von Keyserlingk, and D. M. Weary. 2005. Changes in feeding, drinking, and standing behavior of dairy cows during the transition period. J. Dairy Sci. 88:2454-2461.

Jensen, M. B. 2012. Behavior around the time of calving in dairy cows. Appl. Anim. Behav. Sci. 139:195-202.

Kovács, L., F. L. Kézér, F. Ruff, and O. Szenci. 2017. Rumination time and reticuloruminal temperature as possible predictors of dystocia in dairy cows. J. Dairy Sci. 100:1568-1579.

Lobeck-Luchterhand, K. M., P. R. B. Silva, R. C. Chebel, and M. I. Endres. 2015. Effect of stocking density on social, feeding, and lying behavior of prepartum dairy animals. J. Dairy Sci. 98:240-249.

Mainau, E., and X. Manteca. 2011. Pain and discomfort caused by parturition in cows and sows. Appl. Anim. Behav. Sci. 135:241-251.

Maselyne, J., M. Pastell, P. T. Thomsen, V. M. Thorup, L. Hänninen, J. Vangeyte, A. Van Nuffel, and L. Munksgaard. 2017. Daily lying time, motion index and step frequency in dairy cows change throughout lactation. Res. Vet. Sci. 110:1-3.

Mee, J. F. 2004. Managing the dairy cow at calving time. Vet. Clin. North Am. Food Anim. Pract. 20:521-546.

Mee, J. F. 2008a. Prevalence and risk factors for dystocia in dairy cattle: A review. Vet. J. 176:93-101.

Mee, J. F. 2008b. Newborn dairy calf management. Vet. Clin. North Am. Food Anim. Pract. 24:1-17.

Miedema, H., M. S. Cockram, C. M. Dwyer, and A. I. Macrae. 2011a. Behavioral predictors of the start of normal and dystocic calving in dairy cows and heifers. Appl. Anim. Behav. Sci. 132:14-19.

Miedema, H. M., M. S. Cockram, C. M. Dwyer, and A. I. Macrae. 2011b. Changes in the behavior of dairy cows during the $24 \mathrm{~h}$ before normal calving compared with behavior during late pregnancy. Appl. Anim. Behav. Sci. 131:8-14.

Neave, H. W., J. Lomb, M. A. G. von Keyserlingk, A. Behnam-Shabahang, and D. M. Weary. 2017. Parity differences in the behavior of transition cows. J. Dairy Sci. 100:548-561.

Ostertagová, E. 2012. Modelling using polynomial regression. Procedia Eng. 48:500-506.

Proudfoot, K. L., J. M. Huzzey, and M. A. G. von Keyserlingk. 2009. The effect of dystocia on the dry matter intake and behavior of Holstein cows. J. Dairy Sci. 92:4937-4944.

Schirmann, K., N. Chapinal, D. M. Weary, L. Vickers, and M. A. von Keyserlingk. 2013. Short communication: Rumination and feeding behavior before and after calving in dairy cows. J. Dairy Sci. 96:7088-7092.

Schuenemann, G. M., I. Nieto, S. Bas, K. N. Galvao, and J. Workman. 2011. Assessment of calving progress and reference times for obstetric intervention during dystocia in Holstein dairy cows. J. Dairy Sci. 94:5494-5501.

Theurer, M. E., D. E. Amrine, and B. J. White. 2013. Remote noninvasive assessment of pain and health status in cattle. Vet. Clin. North Am. Food Anim. Pract. 29:59-74.

Wall, E., R. Mrode, G. Banos, and M. Coffey. 2010. Development of calving-ease evaluations for UK Holstein-Friesian cows. Proceedings of BSAS, 69. Br. Soc. Anim. Sci., Edinburgh, UK.

Wehrend, A., E. Hofmann, K. Failing, and H. Bostedt. 2006. Behavior during the first stage of labour in cattle: Influence of parity and dystocia. Appl. Anim. Behav. Sci. 100:164-170.

\section{ORCIDS}

R. A. C. Barraclough ๑ https://orcid.org/0000-0003-3975-3520

D. J. Shaw () https://orcid.org/0000-0003-2016-1541

A. I. Macrae (ㄴ) https://orcid.org/0000-0001-6011-9474 